\title{
PERCEIVED PHYSICAL EXERCISE BENEFITS AND BARRIERS: A KEY TO ENHANCING WELLNESS FOR ALL AGES IN NIGERIA
}

\author{
Offiong, Dominic A.; Ndep, Antor O.; Onyejose, Kenneth; Omang, Joseph A.; and Otu, Fidelis T. \\ Department of Public Health, Faculty of Allied Medical Sciences, University of Calabar, Calabar; Nigeria \\ Corresponding author: asuquooffiong@yahoo.com 07030506122 \\ DOI: $10.31364 /$ SCIRJ/v7.i12.2019.P1219736 \\ http://dx.doi.org/10.31364/SCIRJ/v7.i12.2019.P1219736
}

\begin{abstract}
Background: Exercise is any activity a person engages to promote or maintains physical fitness and overall wellness. Physical inactivity has been associated with 1.9 million preventable deaths yearly, increases risk of mortality by $20-30 \%$ and a major risk factor in increasing the level of obesity. Methods: This study employed a systematic review of literatures on physical exercise benefits and barriers: a key to enhancing wellness for all ages in Nigeria. Results: Empirical findings shows that knowledge and attitude towards physical exercise in most part of Nigeria were reportedly high, but had poor exercise habits. Participating in physical activities has been linked with increased self-efficacy levels, reduced fatigability and improved cardiovascular fitness, reduces risk of depression, improves muscular fitness, improves bone health. However, lack of access to exercise facilities (95.0 $\%)$, economic cost demands of exercise $(94.2 \%)$ and the perception that people in workout clothes look funny (94.2\%) respectively were barriers impeding the engagement in physical exercise; thus recording low physical activity levels (80.2\%). Measuring physical activity as a vital sign; encourage the public to engage in physical activity at least 150 minutes per week. Were some of the strategies for encouraging physical exercise. Conclusion: This review brings to bear the need to promote active lifestyles, among people of all ages. Based on the findings of this review, it was recommended that to enhance wellness, sedentary and inactive lifestyles should be discouraged. Individual no matter the status should be involved in physical activities and recreation which should be organised and last for at least 30 minutes three (3) times a week. In addition to available evidence of sedentary life styles of the majority of the population, introducing intervention programmes such as educational intervention, school based programmes, work-site intervention, intervention by health care providers should be advocated.
\end{abstract}

Key words: physical inactivity, exercise.

\section{Background}

Exercise is any activity a person engages to promote or maintains physical fitness and overall wellness ${ }^{1}$. Individuals engage in it for various reasons which include, enhancing growth and increase strength, prevent aging, muscles building and the cardiovascular system, improving athletic skills, weight loss or maintenance, improving health ${ }^{2}$ and also for pleasure. Most often outdoor exercise is the prefer form where individuals can meet in groups, socialize, and enhance well-being ${ }^{3}$.

According to WHOs' 2011 "all-cause mortality list", physical inactivity and exercise is ranked number fourth out of Tobacco, Alcohol consumption, Unhealthy diet, Overweigh/ Obesity, High blood pressure, High blood cholesterol, High blood glucose, excessive salt intake. Physical inactivity has been associated with 1.9 million preventable deaths yearly ${ }^{4}$ Physical inactivity had been linked with about $3 \%$ of disease burden globally in developed and developing countries; 'more than $20 \%$ of cardiovascular disease and 10\% of strokes' (World Health Report, 2011). Physical inactivity is ranked $10^{\text {th }}$ leading causes of mortality, disabilities and among the leading public health problems of the 21st century. Non-Communicable Diseases (NCDs) account for more than three-quarters of all deaths and more than 25 percent of deaths in most countries in North Africa and subSaharan Africa respectively ${ }^{5}$. Research has shown that the benefits associated with physical activity include reduction in anxiety, lower lipid and cholesterol levels, decrease high blood pressure in adolescents, and various indices of stress among adults especially at the college population. Other benefits include improving aerobic capacity, flexibility, muscular strength, control weight and build bone mass ${ }^{6}$. Increase physical exercise improves patient's life after receiving a cancer treatment ${ }^{7}$.

Physical inactivity has been associated with 1.9 million preventable deaths yearly, increases risk of mortality by $20-30 \%$ and a major risk factor in increasing the level of obesity ${ }^{8}$. Approximately $22 \%$ of the adult population and $59 \%$ of adults in Gambia experience a low level of physical exercise and on average, spend 231 minutes per day on sedentary activities ${ }^{9}$. Even though the benefits of physical activity as stated by researchers; most adults, youth and children in Nigeria live relatively sedentary lifestyle and are not active enough to achieve exercise benefits ${ }^{10}$. 


\section{Methods}

This systematic review of perceived physical exercise benefits and barriers addressed the focused question of knowledge and attitude towards physical exercise in Nigeria and, involved a comprehensive search of the literature with clear inclusion and exclusion criteria for papers included in the review, addressed methodological quality of the papers, and synthesized results by themes. The key words "physical activity," "exercise," and "Nigeria" were used as selection criteria. In addition, journal articles published between 2010 and 2019 were included in the search, which was restricted to articles published in English. The 15 articles that met the inclusion criteria were reviewed and sorted into the following themes: knowledge and attitude towards physical exercise in Nigeria, benefit of physical exercise, benefit of family planning, knowledge of family planning, barriers toward physical exercise practice, and strategies in engaging in physical exercise. When few articles met the criteria for a particular theme, references in those articles were examined.

\section{KNOWLEDGE AND ATTITUDE TOWARDS PHYSICAL EXERCISE IN NIGERIA}

Research has shown that knowledge and attitude towards physical exercise in most part of Nigeria were reportedly high; a study in Western Nigeria using convenience sampling indicated that most of the respondent had sound knowledge (73.65\%) of the benefits of exercise and a positive attitude towards exercise, but had poor exercise habits ${ }^{11}$. Slightly over $50 \%$ of them did not know the different types of exercise that might benefit them. Furthermore, $75.73 \%$ respondents were also found to have knowledge of the health benefits of Physical activity, with a positive attitude at the Federal Medical Centre (FMC), Owo, Nigeria $^{12}$. A study in Gambia using cross sectional study design also reported a Knowledge level found to be generally adequate. Attitude of respondents was collectively high; whereas the engaging in physical exercise was quite low and more than $25 \%$ of the participants spend less than an hour exercising per day ${ }^{13}$.

\section{BENEFIT OF PHYSICAL EXERCISE}

Physical activities are considered very important in contemporary society. The benefits of activities are well documented and these have both physical and physiological benefits. Generally, people who engage in physical activity tend to live longer and are less vulnerable to health problems like heart disease, type 2 diabetes, obesity, and some cancers ${ }^{14}$. For people with chronic diseases, physical activity can help manage these conditions and complications. Participating in physical activities has been linked with enhanced balance and walk, improved reasoning, improved arm recovery and function, increased self-efficacy levels, reduced fatigability and improved cardiovascular fitness ${ }^{15,16}$, Reduces risk of depression, Improves aerobic fitness, Improves muscular fitness, Improves bone health, Promotes favorable body composition, Improves attention and some measures of educational performance (with school physical activity programs) ${ }^{14}$.

\section{BARRIERS TOWARD PHYSICAL EXERCISE PRACTICE}

Research have showed lack of access to exercise facilities $(95.0 \%)$, being uncomfortable to workout (94.2\%), financial cost demands of keeping fit $(94.2 \%)$ and the impression that people in exercise clothes look amusing (94.2\%) respectively as barriers impeding the engagement in physical exercise; thus recording low physical activity levels $(80.2 \%)^{17}$. Other barriers as reported included Intrapersonal barriers such as lack of time, awareness, and enthusiasm; physical presence concerns; wellbeing concerns and fatigue. Interpersonal barriers included family/caregiving errands; lack of social backing; and lack of a physically active partner ${ }^{18}$. Environmental barriers included safety measures; lack of exercise amenities; weather concerns; lack of sidewalks ${ }^{18}$.

\section{STRATEGIES IN ENGAGING IN PHYSICAL EXERCISE}

Countries and communities must take action to provide individuals with more opportunities to be active, in order to increase physical activity. Phillip ${ }^{19}$ stated five strategies in encouraging physical exercise: "1) measure physical activity as a vital sign; 2) encourage patients to be physically active at least 150 minutes per week; 3) create healthy environments by making it easier for patients to be physically active where they live, learn, work, play, and pray; 4) monitor disease incidence of patients who are physically active vs those who are not physically active; and 5) spread best practices". In Nigeria, government policies (such as those that influence health) emanate from three levels; and these include the Federal, state, and local governments. Although the federal ministry of health has a national health promotion draft policy, there is no political will by the Federal Government to moderate or combat the menace of NCDs through promotion of physical activity ${ }^{20}$. Consequently, Nigeria is far from meeting the Healthy People 2020 policy (a 10-year health plan released by the US Department of Health and Human services in 2010) or $10 \%$ reduction in physical inactivity as reported in Canada for year 2003, which recognises physical activity as a leading health indicator ${ }^{20}$. The federal government of Nigeria, established an organisation known as the Nigeria Academicals Sports Committee (NASCOM) which is supervised by National Sports Commission (NSC) whose activities is to work in partnership with both the state and local governments in promoting an initiative on physical activities in secondary schools ${ }^{20}$. This initiative ought to be built upon by the three levels of government as well as the private sector to sustain its impact. Globally, Strategies to tackle physical inactivity were established in about $80 \%$ of WHO Member States, however only $56 \%$ were operational in 2013. Both national and local authorities are adopting guidelines in a range of sectors to promote physical activity $^{21}$. 


\section{CONCLUSION}

This review brings to bear the need to promote active lifestyles, among people of all ages. Clearly, the goals of a more active populace will be challenging as commitment to change on the part of individuals, families and communities will be required. It is worth to note that both public and private sectors will come together to promote fitness and more healthy habits for people of all ages.

\section{RECOMMENDATION}

Based on the findings of this review, it was recommended that to enhance wellness, sedentary and inactive lifestyles should be discouraged. Individual no matter the status should be involved in physical activities and recreation which should be organised and last for at least 30 minutes three (3) times a week. In addition to available evidence of sedentary life styles of the majority of the population, introducing intervention programmes such as educational intervention, school based programmes, work-site intervention, interventions by health care providers, limiting the role of automobiles, promoting walking and bicycle riding, recreation based intervention and initiative at community level will make a strong case for public health efforts to encourage increased participation in physical activity in large numbers to improve fitness and health of the population in building vibrant nation

\section{Reference}

1. Kylasov A, Gavrov S. Diversity of Sport: non-destructive evaluation. Paris: UNESCO:Encyclopedia of Life Support Systems; 2011. pp. 462-91. ISBN 978-5-89317-227-0.

2. Mayo Clinic. "7 great reasons why exercise matters". Retrieved 2 November 2018.

3. Bergstrom, K; Muse, T; Tsai, M; Strangio, S. "Fitness for Foreigners". Slate Magazine. Slate Magazine. Retrieved 5 December 2016.

4. Physical T, Council, A. Participation report the physical activity council's annual study 2016.

5. Wojcicki M. "The effects of physical activity education on exercise self-efficacy and physical activity: a comparison study between exercise science and physical education teacher education" 2012.

6. Ousman B, Modou B. "Assessing the awareness, attitude and practice of students in the public health and education department, university of the gambia". acta scientific medical sciences 3.5 (2019): 52-62.

7. Afif M. "Knowledge, attitude and practice regarding exercise among people exercising in gymnasium and recreational parks around kuantan, Malaysia”. 6.6 (2016): 47-54.

8. Azuhairi A. Physical inactivity and its associated factors among university students 13.10 (2014): 119-130.

9. Policy. Gambia national health policy 2012-2020 (2012).

10. Olubayo-Fatiregun, M. A., Ayodele, R.B, Olorunisola, H.K. Health, Fitness and Physical Activity: A Key to Enhancing Wellness for All Ages in Building a Vibrant Nation. Asian Journal of Humanities and Social Sciences (AJHSS) Volume 2Issue 1, February, 2014 ISSN: 2320-9720 www.ajhss.org 77

11. Odunaiya, N. A, Aderibigbe, A. A, Oguntibeju, O. O. Physical exercise: Knowledge, attitudes and habits of literate women in Western Nigeria; 2011. Vol 17, No 4.

12. Bolarinde, S; Olagbegi, O; Ebenezer, D; Akinrinbola, B. knowledge, attitude and practice of physical activity among health professionals in a Nigerian tertiary health institution. South American Journal of Public Health; 2015.

13. Bajinka, O, Badjan, M. Assessing the Awareness, Attitude and Practice of Students in the Public Health and Education Department; 2019.

14. CDC. 2012. https://www.cdc.gov > physical activity > why-it-matters

15. World Health Organization. World Health Organization definition of physical activity (updated 2014, cited 24.11.2014). Available from: http://www.who.int/topics/physical_activity/en/(accessed 24/11/2014). Google Scholar

16. Saunders D. H, Greig C. A, Mead G. E. Physical Activity and Exercise after Stroke: Review of Multiple Meaningful Benefits. Stroke (serial on the internet) 20 Nov (cited 2014 Nov 14): (about 6 p) Available from: http://www.ncbi.nlm.nih.gov/pubmed/25370588 (Accessed November 12, 2014). Google Scholar 
17. Opeyemi A I, Ade F A, Omoyemi O, Henrietta O F, Olayinka A. Perceived barriers to physical activity among Nigerian stroke survivor. The Pan African Medical Journal; 2015 - ISSN 1937-8688

18. Joseph R. P, Ainsworth B. E, Keller C, and Dodgson J. E. Barriers to Physical Activity Among African American Women: An Integrative Review of the Literature; 2015. 55(6):679-99. doi: 10.1080/03630242.201

19. Phillip T. Strategies to Increase Physical Activity. Perm J. 2015 Fall; 19(4): 84-88.doi: 10.7812/TPP/14-242

20. Damilola A. Physical inactivity in Nigeria: A short analysis (part 2 of 2). Posted on September 21, 2012; Guest blog by https://blogs.bmj.com/bjsm/2012/09/21/

21. WHO. Physical activity; 2018. Access via https://www.who.int/news-room/fact-sheets/detail/physical-activity 